\title{
Causes of change in Northern Hemisphere winter meridional winds and regional hydroclimate
}

\author{
Isla R. Simpson ${ }^{1 \star \dagger}$, Richard Seager ${ }^{1}$, Mingfang Ting ${ }^{1}$ and Tiffany A. Shaw ${ }^{1,2,3}$
}

A critical aspect of human-induced climate change is how it will affect precipitation around the world. Broadly speaking, warming increases atmospheric moisture holding capacity, intensifies moisture transports and makes sub-tropical dry regions drier and tropical and mid-to-high-latitude wet regions wetter $^{1,2}$. Extra-tropical precipitation patterns vary strongly with longitude, however, owing to the control exerted by the storm tracks and quasi-stationary highs and lows or stationary waves. Regional precipitation change will, therefore, also depend on how these aspects of the circulation respond. Current climate models robustly predict a change in the Northern Hemisphere (NH) winter stationary wave field that brings wetting southerlies to the west coast of North America, and drying northerlies to interior southwest North America and the eastern Mediterranean ${ }^{3-5}$. Here we show that this change in the meridional wind field is caused by strengthened zonal mean westerlies in the sub-tropical upper troposphere, which alters the character of intermediate-scale stationary waves. Thus, a robust and easily understood model response to global warming is the prime cause of these regional wind changes. However, the majority of models probably overestimate the magnitude of this response because of biases in their climatological representation of the relevant waves, suggesting that winter season wetting of the North American west coast will be notably less than projected by the multi-model mean.

Stationary waves arise from longitudinal asymmetries in topography, diabatic heating and transient eddy heat and vorticity fluxes. The character of the forced waves depends not only on these asymmetric forcings, but also on the zonal mean flow and nonlinear wave-wave interaction, with the additional complication that the asymmetric forcings and zonal mean flow are, in turn, affected by the stationary waves ${ }^{6}$. In the $\mathrm{NH}$ winter, climate models predict that stationary wave changes will form an important component of mid-latitude circulation change $\mathrm{e}^{7-9}$ and past studies have variously attributed these changes to altered wave forcing from the tropics ${ }^{8,10-12}$ or an altered zonal mean basic state in which the stationary wave activity propagates ${ }^{7,13,14}$, with a decisive explanation remaining elusive.

Here, we focus on the latest model projections of future eddy meridional wind $\left(v^{*}\right)$, given its importance for regional hydroclimate ${ }^{5}$. Figure 1 presents an analysis of the Future-Past difference simulated by 35 Coupled Model Intercomparison Project, phase 5 (CMIP5) models (see Methods). The $300 \mathrm{hPa}$ response (Fig. 1b) is dominated by an approximately zonal wavenumber 5 pattern, reminiscent of the circumglobal teleconnection pattern prevalent in natural variability ${ }^{15}$. It is fairly barotropic (Fig. 1c) and, over North America, the low-level west coast southerlies and interior southwest northerlies contribute to wetting the US west coast and drying the interior southwest ${ }^{5}$. Such a response has been identified in a number of past studies ${ }^{8,11,12}$ and its structure is robust across the models, but there is a wide spread in magnitude (Fig. 1d). The implications of this spread for North American hydroclimate are seen in Fig. 1e, where the models are divided based on the strength of the $300 \mathrm{hPa}$ interior southwest $v^{*}$ anomaly. The stronger half exhibits more west coast wetting and southern drying, as would be expected given the mean flow contributions to this precipitationevaporation $(\mathrm{P}-\mathrm{E})$ change $^{5}$. The relationship between $v^{*}$ and $\mathrm{P}-\mathrm{E}$ is presented in this format for use in the following analysis, but a similar assessment through correlation between southwest $v^{*}$ and P-E exhibits similar features, with a correlation with west coast wetting of up to 0.77 and southwest drying of up to 0.56 .

To understand the multi-model mean response-and consequently the model spread-we turn to simulations with a stationary wave model that simulates the response to given forcings in the presence of a prescribed zonal mean basic state (see Methods). This idealized modelling set-up has limitations but allows the response to be decomposed to help identify causality $6,10,13,14$. When forced by orography, heating and transient eddies, the main features of the $300 \mathrm{hPa}$ Past climatology are reproduced, albeit with some discrepancies (compare Figs 2a and 1a). The mid-latitude Future-Past difference is also well reproduced (Fig. 2b), including the southerlynortherly-southerly pattern across the Americas (although shifted slightly west) and the European/Asian anomalies. The main discrepancies exist in the south Pacific and high latitudes-away from our region of interest. Further experiments reveal that much of the mid-latitude $v^{*}$ response can be reproduced by changing only the basic state (Fig. 2c). A secondary contribution arises from the altered diabatic heating, but is more appropriately considered a feedback to the presence of the wave (Supplementary Fig. 2). Therefore, for the mid-latitude $v^{*}$ features considered here, the altered zonal mean basic state is the primary driver.

This anomalous basic state (Supplementary Fig. 1) consists of: amplified Arctic warming and associated high-latitude easterlies; polar lower stratospheric cooling, tropical upper tropospheric warming and associated sub-tropical upper tropospheric westerlies; and a poleward shift of the lower tropospheric westerlies. To assess the relative importance of these components, we modify a thermal wind balanced basic state, constructed from the zonal mean temperature anomalies (see Methods), which behaves similarly to the actual basic state change (compare Figs $3 \mathrm{a}$ and $2 \mathrm{c}$ ). The mid-latitude $v^{*}$ response is largely unaffected by the removal of

\footnotetext{
${ }^{1}$ Lamont-Doherty Earth Observatory, Columbia University, Palisades, New York 10964, USA. ${ }^{2}$ Department of Applied Physics and Applied Mathematics, Columbia University, New York, New York 10027, USA. ${ }^{3}$ Department of Geophysical Sciences, University of Chicago, Chicago, Illinois 60637, USA. †Present address: Climate and Global Dynamics Division, National Center for Atmospheric Research, Boulder, Colorado 80307, USA. 


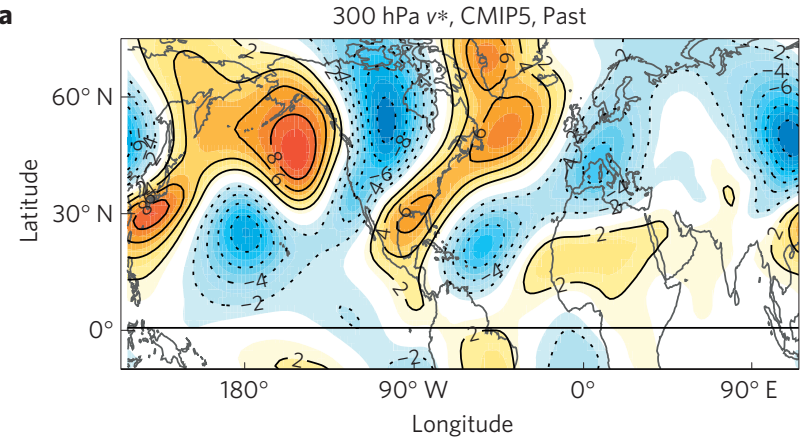

b

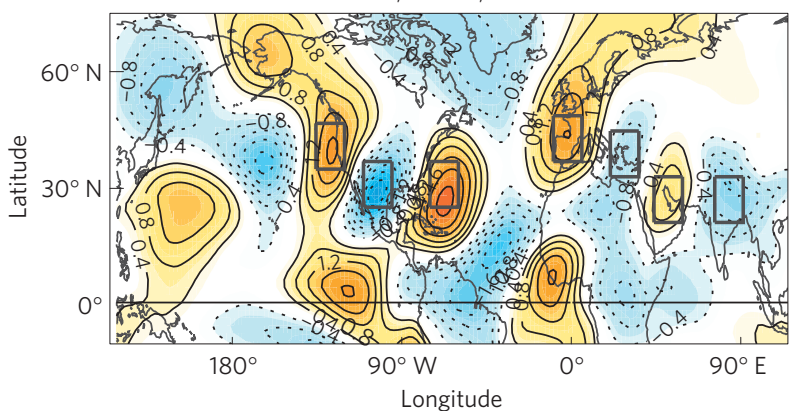

c

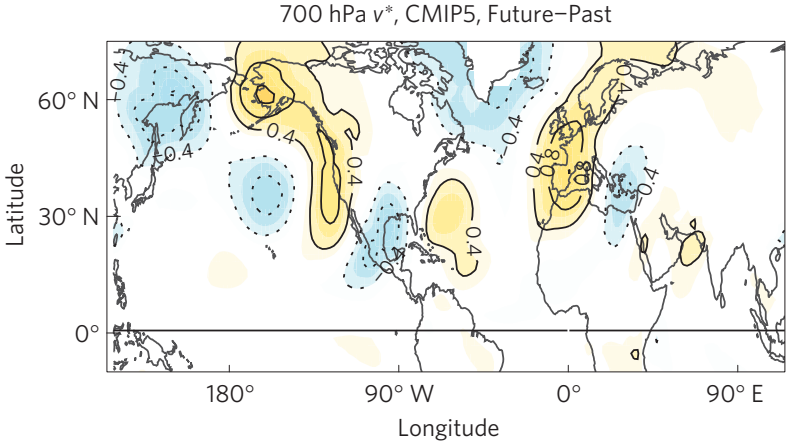

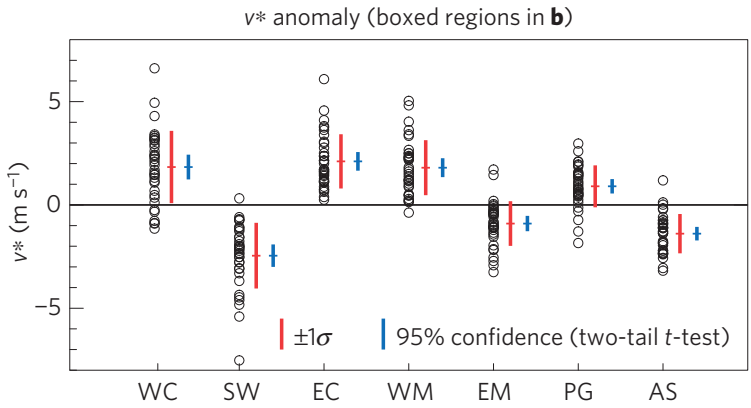

e
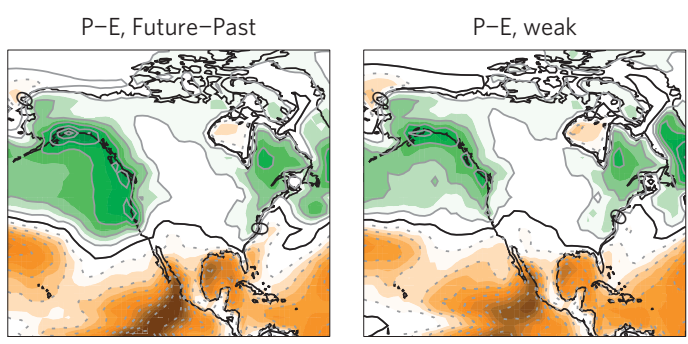

$\mathrm{P}-\mathrm{E}$, strong-weak
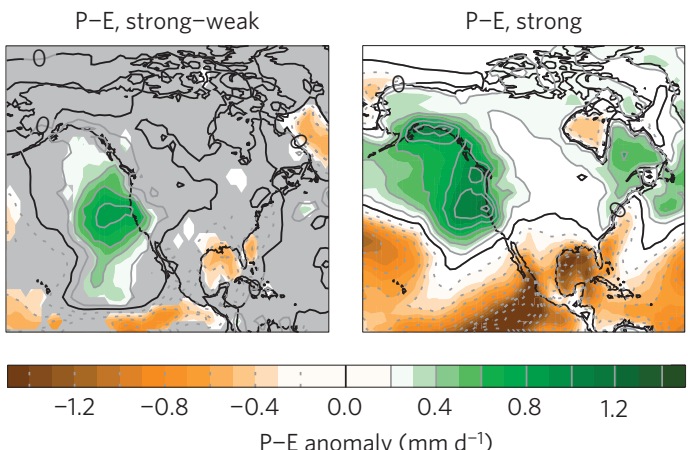

Figure 1 | The DJF $v^{*}$ response to climate change. a,b, Multi-model mean $300 \mathrm{hPa} v^{*}$ for Past (a, contour $\left.=2 \mathrm{~m} \mathrm{~s} \mathrm{~s}^{-1}\right)$ and Future-Past

(b, contour $=0.4 \mathrm{~m} \mathrm{~s}^{-1}$ ). $\mathbf{c}$, As for $\mathbf{b}$ at $700 \mathrm{hPa}$. $\mathbf{d}, 300 \mathrm{hPa} v^{*}$ anomaly for each model in the seven boxed regions in $\mathbf{b}$. These characterize the response over: the North American west coast (WC), interior southwest (SW) and east coast (EC), the Western and Eastern Mediterranean (WM and EM), the Persian Gulf (PG) and central Asia (AS). e, The P-E response for (top left) CMIP5 multi-model mean, (top right and bottom right) models in the weakest and strongest halves of the $v^{*}$ distribution in the SW box, respectively, and (bottom left) the difference between the strong and weak responses (grey not statistically significant at the $95 \%$ level by a two-tailed $t$-test).

Arctic amplification, polar lower stratospheric cooling and lower tropospheric anomalies (Fig. 3b). The main features only require the tropical upper tropospheric warming and associated sub-tropical upper tropospheric westerly acceleration. This tropical temperature response is produced primarily from moist adiabatic adjustment in the tropics ${ }^{16}$, with further contributions from transient-eddy-driven zonal mean circulation change $\mathrm{e}^{17}$.

Further experiments (Supplementary Fig. 3) reveal that it is the acceleration of the winds that is key to the $v^{*}$ response, not the altered meridional structure. According to linear theory of barotropic Rossby waves in a zonal flow ${ }^{18,19}$ (Methods), the zonal mean wind governs the properties of the stationary waves, with the atmosphere supporting those with a total wavenumber

$$
K_{s}=\sqrt{k^{2}+l^{2}}=\sqrt{\frac{\beta-[u]_{y y}}{[u]}}
$$

where $k=$ zonal wavenumber, $l=$ meridional wavenumber, $\beta=$ the meridional gradient of the Coriolis parameter and $[u]=$ zonal mean zonal wind. In accordance with the climatological $K_{\mathrm{s}}$ (Fig. 4a), a zonal wavenumber decomposition of the Past climatological $v^{*}$ (Fig. 4c) indicates that only stationary waves with $k$ less than approximately 7 are prevalent. The dispersion of barotropic stationary Rossby wave energy follows the zonal $\left(c_{x}\right)$ and meridional $\left(c_{y}\right)$ group velocities:

$$
c_{x}=\frac{2[u] k^{2}}{\left(k^{2}+l^{2}\right)}, \quad c_{y}=\frac{2[u] k l}{\left(k^{2}+l^{2}\right)}
$$

with $k$ being constant following a ray path, $l$ adapting to the background $K_{\mathrm{s}}$ and the ratio of meridional to zonal propagation given by $c_{y} / c_{x}=l / k$ (ref. 18). This implies that larger zonal scales (small $k$ ) propagate more meridionally, whereas intermediate scales propagate more zonally and can exist only where $K_{\mathrm{s}}$ is sufficiently high. Accordingly, the highest $v^{*}$ amplitude lies between $25^{\circ} \mathrm{N}$ and $40^{\circ} \mathrm{N}$ for the intermediate scales but lies further north and south for the larger scales, as they approach their turning latitude ${ }^{18}$ (Fig. 4c). There is, therefore, motivation to distinguish between these different scales: $k \leq 3$ (large-scale meridionally propagating modes) and $k \geq 4$ (intermediate-scale, meridionally trapped modes). 
a

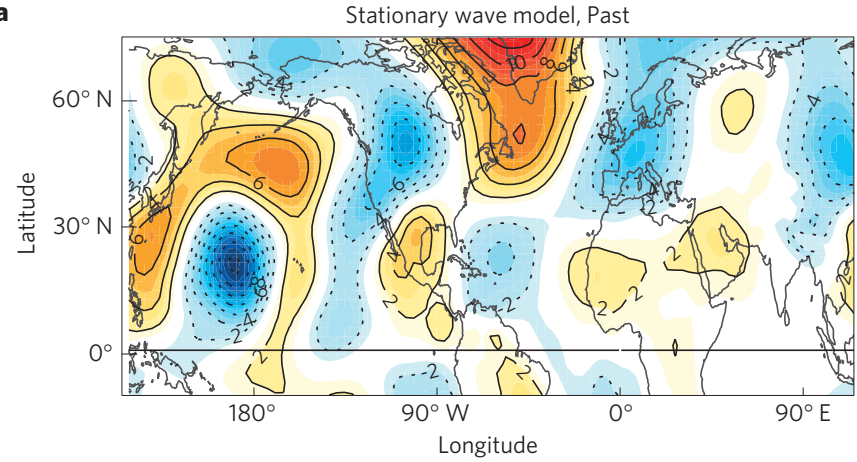

b

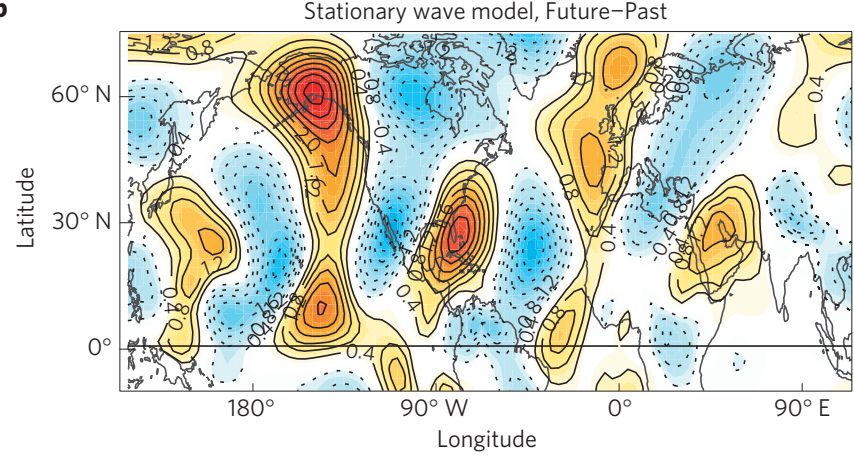

c

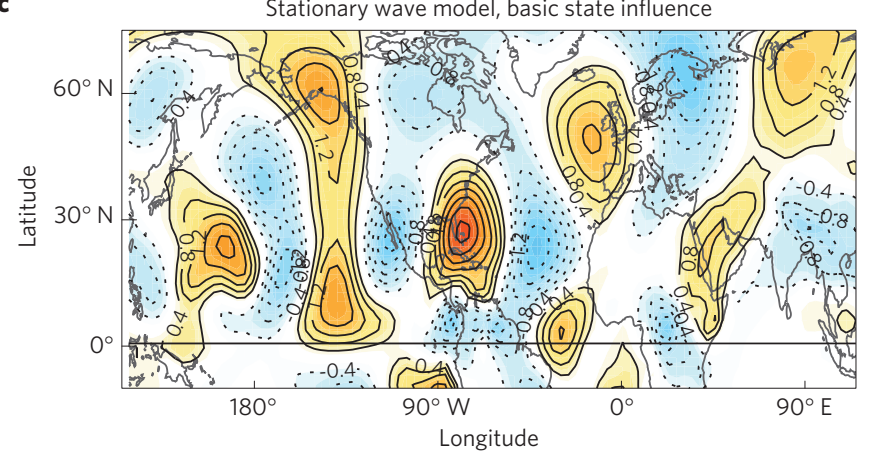

Figure 2 | $300 \mathrm{hPa} v^{*}$ from stationary wave model simulations

(see Methods). a, Past climatology (contour $=2 \mathrm{~m} \mathrm{~s}^{-1}$ ). b, Future-Past difference (contour $=0.4 \mathrm{~m} \mathrm{~s}^{-1}$ ). $\mathbf{c}$, Influence of the altered zonal mean basic state (contour $=0.4 \mathrm{~m} \mathrm{~s}^{-1}$ ). See Supplementary Fig. 2 for the remaining contributions.

Figure 4e,f,h shows the $300 \mathrm{hPa} v^{*}$ Past climatology, Future-Past difference and observationally based reanalysis climatology ${ }^{20}$ for $k \geq 4$. These scales make a small contribution to the Past climatology (compare Figs $4 \mathrm{e}$ and 1a), but are primarily responsible for the Future-Past difference of interest here. The wavenumber spectrum difference (Fig. 4d) shows that, within the zonal wavenumber range $4-6$, between $30^{\circ}$ and $50^{\circ} \mathrm{N}$, there is a shift to longer zonal scales (highlighted by the red ellipse). This is similarly produced in the stationary wave model (Supplementary Fig. 4). Figure $4 \mathrm{c}-\mathrm{g}$ together indicates that a lengthening of these intermediate-scale waves accounts for the $v^{*}$ anomalies, over North America in particular, with additional effects downstream. This lengthening is expected. As $[u]$ accelerates, $K_{s}$ reduces (equation (1), Fig. 4b) and Fig. 4d indicates that the stationary wave field adapts to this change through reducing $k$. Also, an accelerated zonal group velocity of the supported waves in the presence of increased $[u]$ (equation (2)) results in wave activity travelling further east from the source before being dissipated. Refraction may contribute to some of the change in $k=4$, as Fig. $4 \mathrm{~d}$ demonstrates a southward shift of the $k=4$ presence. But this is not well captured by the stationary wave model (Supplementary Fig. 4) and, as the latter can reproduce the main features of the $v^{*}$ response, this aspect must be of secondary importance.

So, overall, a lengthening of the intermediate-scale stationary waves in the presence of accelerated sub-tropical westerlies appears as the dominant effect. This does not rely on an uncertain process, such as the redistribution of tropical precipitation ${ }^{21,22}$. It relies on the accelerated $[u]$ : a feature of climate change that is robust across models and expected, given a warming of the tropical upper troposphere. Assuming models can realistically simulate tropical tropospheric temperature responses (as supported by the evidence to date $\mathrm{e}^{23}$ ), and given that these intermediate-scale waves exist in the real atmosphere (Fig. 4h), we can expect it to be a feature of humaninduced climate change.

There is, however, a large model spread in response magnitude, with important consequences for North American hydroclimate. On the basis of the proposed mechanism, two factors may affect the magnitude: the climatological intermediate-scale wave amplitude and the upper tropospheric $[u]$ increase. Figure $5 \mathrm{a}$ relates the $300 \mathrm{hPa} v^{*}$ response over the interior southwest with the Past climatological wave amplitudes in the grey box in Fig. 4e. Models with larger amplitude climatological waves exhibit a larger southwest $v^{*}$ response, with about $37 \%$ of the model variance explained by this relationship. Figure $5 \mathrm{~b}$ indicates that models with a larger $[u]$ acceleration also exhibit a larger amplitude response, but this explains much less variance. However, taken together, these two predictors explain almost half the variance (Fig. 5c). Natural variability ${ }^{24}$ and differences in asymmetric forcing changes probably contribute to the remaining model spread.

The climatological wave amplitude in the observationally based reanalysis lies at the low end of the modelled range (Fig. 5a). Taking the reanalysis wave amplitude, the range of model predicted [ $u$ ] anomalies and the Fig. $5 \mathrm{c}$ regression coefficients, we hypothesize that the real world response will lie within the grey shaded region in Fig. $5 c$, which encompasses roughly the weaker half of the models. If so, the P-E changes of the weaker half (Fig. 1e) will be more realistic, implying the real world is unlikely to become as wet in the west, or dry in the interior southwest, as many of the models or the multi-model mean predict. A complete understanding of the tendency for models to overestimate the wave amplitudes is beyond the scope of this study, but Supplementary Fig. 5 indicates that the southern portion of the waves tends to be too large from the outset at their apparent source in the vicinity of Tibet. This points towards a discrepancy in the source of waves from this region.

Although the main focus here has been on North America, the proposed mechanism also accounts for much of the $v^{*}$ response over Europe and Asia. This is probably contributing to the drying in the eastern Mediterranean, although the altered divergent circulation associated with the more zonally symmetric Hadley cell response is also important there $e^{4,25,26}$. Further work is needed to fully understand the variance in this wave response over Europe, its contribution to hydroclimate change there and how the anomalies over Europe are connected with those over North America. The multi-model mean response in Fig. 4f is suggestive of a downstream extension of the modification to the Pacific waves. However, a model with a large amplitude response over North America does not necessarily have a large amplitude response over Eurasia (Supplementary Table 1). The climatological mean flow may affect the nature of the downstream teleconnections or additional waves originating in the Rockies/North American region may be contributing. It should finally be noted that the proposed mechanism applies primarily to the $v^{*}$ response, which is dominated by the intermediate scales. The zonal asymmetries in the zonal wind response ${ }^{9}$ are dominated by the largerscale, meridional propagating waves, and this aspect requires further investigation. 
a
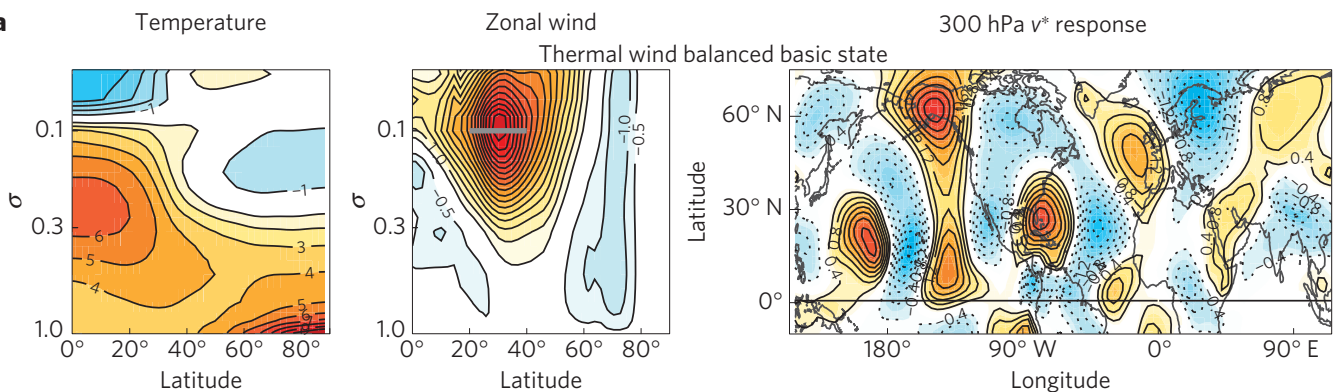

No Arctic amplification, polar lower stratospheric cooling, or lower tropospheric wind anomalies
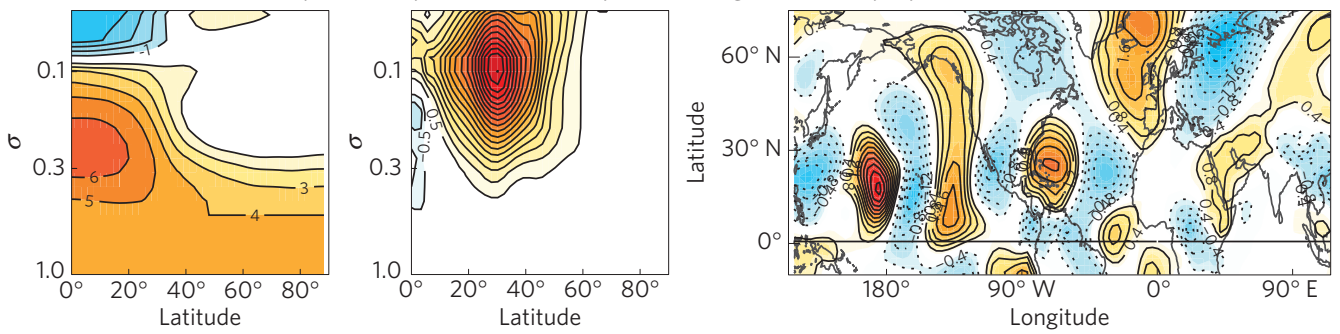

Figure 3 | Testing the influence of different aspects of the basic state change. (Left) zonal mean temperature basic state input for the stationary wave model on model $\sigma$ levels (note the log scale), (middle) same but for the zonal mean zonal wind and (right) the $300 \mathrm{hPa} v^{*}$ response. a, Imposing the full temperature response and the thermal wind balanced zonal wind field. b. Removing Arctic amplification, polar lower stratospheric cooling and lower tropospheric temperature gradients and wind anomalies (see Methods). Contour intervals are (left) $1 \mathrm{~K}$, (middle) $0.5 \mathrm{~m} \mathrm{~s}^{-1}$ and (right) $0.4 \mathrm{~m} \mathrm{~s}^{-1}$. The grey line in the middle panel of $\mathbf{a}$ indicates the averaging region used in Fig. 5.

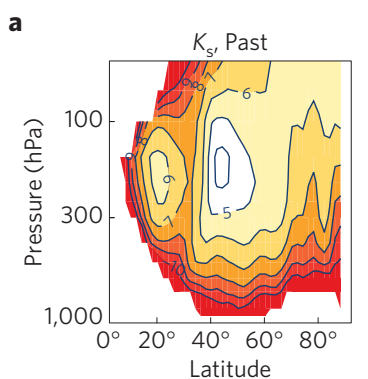

b

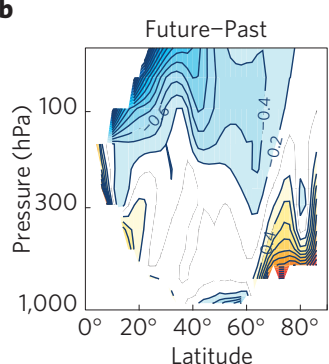

C

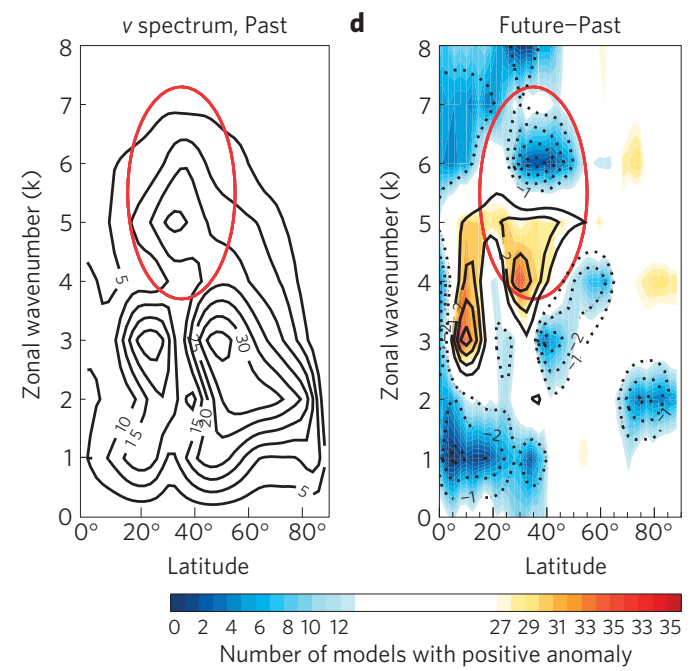

e

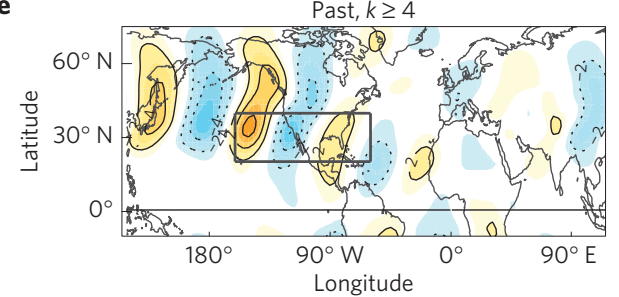

$\mathbf{f}$

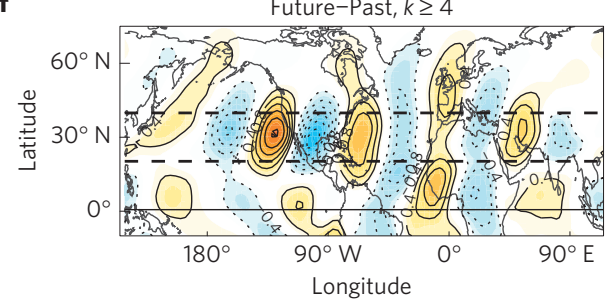

g

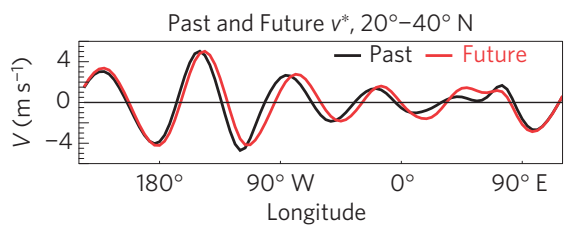

h

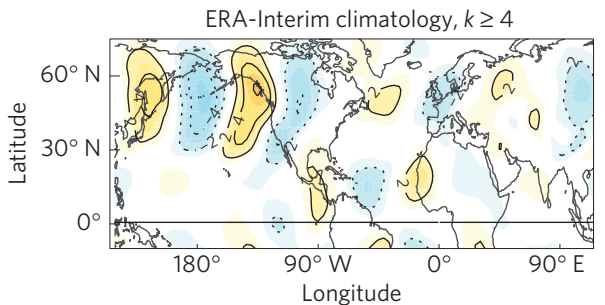

Figure 4 | Demonstrating the lengthening of intermediate-scale stationary waves. a-g, CMIP5 multi-model mean. a,b, Barotropic stationary wavenumber $\left(K_{\mathrm{s}}\right)$ for Past and Future-Past, respectively. $\mathbf{c}, \mathbf{d}$, Zonal mean root mean square amplitude of $300 \mathrm{hPa} v^{*}$ as a function of zonal wavenumber for Past and Future-Past, respectively. Red/blue shading in $\mathbf{d}$ indicates consensus on positive/negative anomalies. e, Past $300 \mathrm{hPa} v^{*}$ for $k \geq 4$. f, As e but for Future-Past. $\mathbf{g}, 20^{\circ}-40^{\circ} \mathrm{N}$ (dashed lines in $\mathbf{f}$ ) averaged $300 \mathrm{hPa} v^{*}$ for Past and Future. h, ERA-Interim $300 \mathrm{hPa} v^{*}$ for $k \geq 4$. The grey box in e denotes the averaging region for Fig. 5 and the red ellipses in $\mathbf{c}$ and $\mathbf{d}$ highlight the region focused on in the text. 


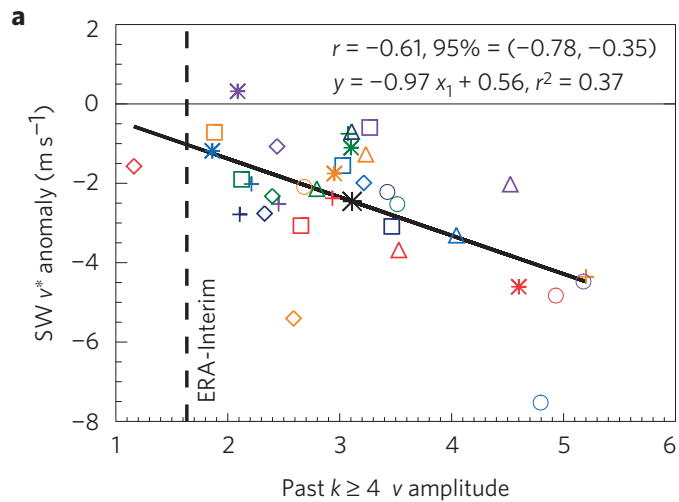

c

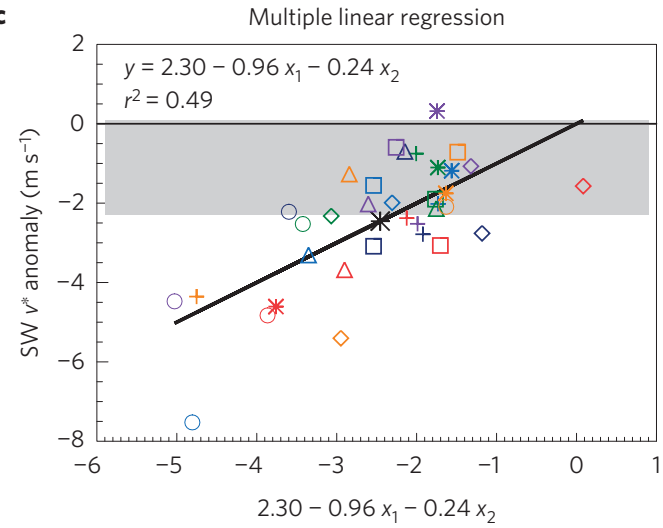

b

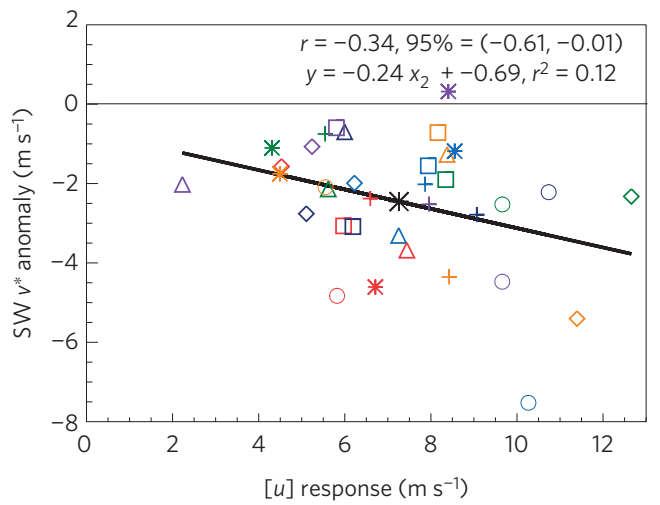

+ ACCESS1-0

+ ACCESS1-3

+ bcc-csm1-1

+ bcc-csm1-1-m

+ BNU-ESM

+ CanESM2

$\checkmark$ CCSM4

$\checkmark$ CESM1-CAM5

$\diamond$ CESM1-WACCM

$\diamond \mathrm{CMCC}-\mathrm{CM}$

$\triangle \mathrm{CMCC}-\mathrm{CMS}$

$\diamond \mathrm{CNRM}-\mathrm{CM} 5$

$\triangle$ CSIRO-Mk3-6-0
$\triangle$ FGOALS-g2
$\triangle$ FIO-ESM
$\triangle$ GFDL-CM3
$\triangle$ GFDL-ESM2G
$\triangle$ GFDL-ESM2M
$\square$ GISS-E2-H
$\square$ GISS-E2-R
$\square$ HadGEM2-AO
$\square$ HadGEM2-CC
$\square$ HadGEM2-ES
$\square$ inmcm4

I IPSL-CM5A-LR

○ IPSL-CM5A-MR

I IPSL-CM5B-LR

- MIROC5

O MIROC-ESM

O MIROC-ESM-CHEM

* MPI-ESM-LR

* MPI-ESM-MR

* MRI-CGCM3

* NorESM1-M

* NorESM1-ME

* Multi-model mean

Figure 5 | Understanding the model spread over North America. Regression of Future-Past $300 \mathrm{hPa}$ SW v* (see Fig. 1) against Past root mean square $v^{*}$ amplitude for $k \geq 4$ averaged over $160^{\circ}-60^{\circ} \mathrm{W}, 20^{\circ}-40^{\circ} \mathrm{N}$ (grey box in Fig. 4e) (a) and Future-Past $[u]$ at $100 \mathrm{hPa}, 20^{\circ}-40^{\circ} \mathrm{N}$ (grey line in Fig. 3 top middle) (b). c, Multiple linear regression against both these variables. ERA-Interim wave amplitudes are indicated by the dashed line in $\mathbf{a}$. Grey shading in $\mathbf{c}$ denotes the range of $v^{*}$ anomalies that would be expected given these amplitudes, the regression coefficients and the CMIP5 range in [u] anomalies. Correlation coefficients $(r)$ and their $95 \%$ confidence interval, calculated by the Fisher transform ${ }^{27}$, are quoted in $\mathbf{a}$ and $\mathbf{b}$. Linear/multiple linear regression lines and the fraction of variance explained $\left(r^{2}\right)$ are also quoted in each panel.

In summary, across North America, projected hydroclimate change depends importantly on the meridional wind response. The explanation of this in terms of accelerated zonal mean zonal winds suggests that this meridional wind response and associated hydroclimate change should be a robust aspect of climate change. However, many models are probably overestimating its magnitude. Although improving this aspect of model dynamics should be a priority, this understanding narrows the uncertainty in future North American hydroclimate and suggests that winter wetting of the west coast and drying of the interior southwest may be weaker than projected by the majority of models.

\section{Methods}

Methods and any associated references are available in the online version of the paper.

Received 23 March 2015; accepted 3 August 2015; published online 7 September 2015

\section{References}

1. Held, I. M. \& Soden, B. J. Robust responses of the hydrological cycle to global warming. J. Clim. 19, 5686-5699 (2006).

2. Seager, R., Naik, N. \& Vecchi, G. A. Thermodynamic and dynamic mechanisms for large-scale changes in the hydrological cycle in response to global warming. J. Clim. 23, 4651-4668 (2010).

3. Neelin, J. D., Langenbrunner, B., Meyerson, J. E., Hall, A. \& Berg, N. California winter precipitation change under global warming in the Coupled Model Intercomparison Project phase 5 ensemble. J. Clim. 26, 6238-6256 (2013).

4. Seager, R. et al. Causes of increasing aridification of the Mediterranean region in response to rising greenhouse gases. J. Clim. 27, 4655-4676 (2014).
5. Seager, R. et al. Dynamical and thermodynamical causes of large-scale changes in the hydrological cycle over North America in response to global warming. J. Clim. 27, 7921-7948 (2014).

6. Held, I. M., Ting, M. \& Wang, H. Northern winter stationary waves: Theory and modeling. J. Clim. 15, 2125-2144 (2002).

7. Brandefelt, J. \& Körnich, H. Northern Hemisphere stationary waves in future climate projections. J. Clim. 21, 6341-6353 (2008).

8. Haarsma, R. J. \& Selten, F. Anthropogenic changes in the Walker circulation and their impact on the extra-tropical planetary wave structure in the Northern Hemisphere. Clim. Dynam. 39, 1781-1799 (2012).

9. Simpson, I. R., Shaw, T. A. \& Seager, R. A diagnosis of the seasonally and longitudinally varying midlatitude circulation response to global warming. J. Atmos. Sci. 71, 2489-2515 (2014).

10. Stephenson, D. B. \& Held, I. M. GCM response of northern winter stationary waves and storm tracks to increasing amounts of carbon dioxide. J. Clim. 6, 1859-1870 (1993).

11. Selten, F. M., Branstator, G. W., Dijkstra, H. A. \& Kliphuis, M. Tropical origins for recent and future Northern Hemisphere climate change. Geophys. Res. Lett. 31, L21205 (2004).

12. Branstator, G. \& Selten, F. “Modes of Variability” and climate change. J. Clim. 22, 2639-2658 (2009).

13. Joseph, R., Ting, M. \& Kushner, P. J. The global stationary wave response to climate change in a coupled GCM. J. Clim. 17, 540-556 (2004).

14. Wang, L. \& Kushner, P. J. Diagnosing the stratosphere-troposphere stationary wave response to climate change in a general circulation model. J. Geophys. Res. 116, D16113 (2011).

15. Branstator, G. Circumglobal teleconnections, the jet stream waveguide and the North Atlantic Oscillation. J. Clim. 15, 1893-1910 (2002).

16. Manabe, S. \& Wetherald, R. T. The effects of doubling the $\mathrm{CO}_{2}$ concentration on the climate of a general circulation models. J. Atmos. Sci. 32, 3-15 (1975).

17. Wu, Y., Seager, R., Ting, M., Naik, N. \& Shaw, T. A. Atmospheric circulation response to an instantaneous doubling of Carbon Dioxide. Part 1: Model experiments and transient thermal response in the troposphere. J. Clim. 25, 2862-2879 (2011). 
18. Hoskins, B. J. \& Karoly, D. J. The steady linear response of a spherical atmosphere to thermal and orographic forcing. J. Atmos. Sci. 38, 1179-1196 (1981).

19. Held, I. M. in Large-Scale Dynamical Processes in the Atmosphere (eds Hoskins, B. J. \& Pearce, R. P.) 127-128 (Academic Press, 1983).

20. Dee, D. P. et al. The ERA-Interim reanalysis: Configuration and performance of the data assimilation system. Q. J. R. Meteorol. Soc. 137, 553-597 (2011).

21. Ma, J. \& Xie, S.-P. Regional patterns of sea surface temperature change: A source of uncertainty in future projections of precipitation and atmospheric circulation. J. Clim. 26, 2482-2501 (2013).

22. He, J., Soden, B. J. \& Kirtman, B. The robustness of the atmospheric circulation and precipitation response to future anthropogenic surface warming. Geophys. Res. Lett. 41, 2614-2622 (2014).

23. Thorne, P. W., Lanzante, J. R., Peterson, T. C., Seidel, D. J. \& Shine, K. P. Tropospheric temperature trends: History of an ongoing controversy. WIREs Clim. Change 2, 66-88 (2011).

24. Deser, C., Phillips, A., Bourdette, V. \& Teng, H. Uncertainty in climate change projections: The role of internal variability. Clim. Dynam. 38, 527-546 (2012).

25. Lu, J., Vecchi, G. A. \& Reichler, T. Expansion of the Hadley cell under global warming. Geophys. Res. Lett. 34, L06805 (2007).

26. Scheff, J. \& Frierson, D. M. W. Robust future precipitation declines in CMIP5 largely reflect the poleward expansion of model subtropical dry zones. Geophys. Res. Lett. 38, L18704 (2012).

27. Devore, J. L. Probability and Statistics for Engineering and the Sciences 5th edn, 535-536 (Brooks/Cole, 1999).

\section{Acknowledgements}

We are grateful to $\mathrm{H}$. Liu and N. Henderson for maintaining the LDEO CMIP-5 archive that houses most of the data used in this study. This work was funded by NSF awards AGS-1317469 and AGS 1243204. TAS acknowledges funding from NSF CAREER award AGS-1538944 and the David and Lucile Packard Foundation. We acknowledge the World Climate Research Programme's Working Group on Coupled Modelling, which is responsible for CMIP, and we thank the climate modelling groups listed in Supplementary Table 1 for producing and making available their model output. For CMIP the US Department of Energy's Program for Climate Model Diagnosis and Intercomparison provides coordinating support and led development of software infrastructure in partnership with the Global Organization for Earth System Science Portals.

\section{Author contributions}

All authors conceived of the study. I.R.S. conducted the analysis and modelling and all authors contributed to the interpretation of results. M.T. provided the stationary wave model code and advice on its set-up and I.R.S. wrote the manuscript with input from all authors.

\section{Additional information}

Supplementary information is available in the online version of the paper. Reprints and permissions information is available online at www.nature.com/reprints.

Correspondence and requests for materials should be addressed to I.R.S.

\section{Competing financial interests}

The authors declare no competing financial interests. 


\section{Methods}

CMIP5 analysis. 35 models from the CMIP5 archive are analysed (Supplementary Table 1). The 'Past' is defined as 1979-2005 of the historical simulation and the 'Future' as 2070-2099 of the RCP8.5 scenario. Model ensemble averages are calculated first. The December, January, February (DJF) meridional wind $(v)$, zonal wind $(u)$, precipitation $(\mathrm{P})$ and evaporation $(\mathrm{E})$ are used in

Figs 1, 4 and 5. Comparison is made with the 1979-2005 ERA-Interim reanalysis climatology ${ }^{20}$.

Stationary wave modelling. Figures 2 and 3 present results using an idealized stationary wave model. This model, described in detail in ref. 28 , is a time-dependent baroclinic model that solves the nonlinear primitive equations for deviations from a prescribed zonal mean basic state in response to zonally asymmetric imposed forcings. We use 24 vertical sigma $(\sigma)$ levels and and rhomboidal truncation at wavenumber 30 in the horizontal (R30). Rayleigh friction is applied to the zonal and meridional winds at the lowest four levels with timescales of $0.3,0.5,1$ and 8 days (shortest at the surface). To prevent baroclinic instability, an interior Rayleigh drag is imposed with a 15-day timescale along with a strong biharmonic diffusion (coefficient of $1 \times 10^{17}$ ) and a 15-day Newtonian relaxation of the temperature field towards the basic state (similar to ref. 6). The influence of damping timescales was tested between 10 and 30 days and results were found to be insensitive over this range. Time integration is performed for 80 days with a relaxation of the zonal mean back to the basic state on a 3-day timescale. A quasi-steady state is reached by day 30 and the average from days 30 to 80 is shown.

The stationary wave model inputs are those of the CMIP5 multi-model mean (Supplementary Fig. 1). The basic state consists of $u, v$, temperature $(T)$ and surface pressure $\left(p_{\mathrm{s}}\right)$, first linearly interpolated onto the model $\sigma$ levels before taking the zonal- and multi-model mean. Diabatic heating is derived as a residual from the thermodynamic equation on pressure levels using monthly mean fields, and therefore includes the sub-monthly transient eddy sensible heat flux convergence. Leaving these thermal forcings combined is considered reasonable given the close linkage between the transient eddy sensible and latent heat fluxes and the tendency for the transients to act diffusively on temperature gradients induced by other diabatic sources ${ }^{6,29}$. The transient vorticity and divergence flux convergences are obtained for a subset of 17 models using the 6-hourly hybrid level $u$ and $v$ after first interpolating onto 17 pressure levels (as ref. 9). As high temporal resolution vertical velocities are not available, the contribution from the vertical eddy fluxes is neglected.
The Future-Past difference (Fig. 2b) is obtained by first running a simulation with the Past basic state, diabatic heating, transient vorticity/divergence forcing and orography (Fig. 2a), followed by a simulation with the future basic state, diabatic heating, transient vorticity/divergence forcing and orography, and then differencing. The contribution from the anomalous basic state, diabatic heating or transient fluxes is assessed by Future simulations in which only the Future input of interest is used and all other inputs are kept at Past values.

In Fig. 3, to assess the relative importance of particular aspects of future temperature change to the basic state influence, a thermal wind balanced zonal mean basic state is constructed. Here, the Future basic state consists of the zonal mean Past $u, v, T$ and $p_{\mathrm{s}}$ plus the Future-Past difference in zonal mean $T$ and the corresponding thermal wind balanced $u$ anomaly. Poleward of $15 \mathrm{~N} / \mathrm{S}$, this $u$ anomaly is obtained by integration of the meridional temperature gradient upward from the multi-model mean near-surface wind anomaly using thermal wind balance. This is pieced together with the actual wind anomaly equatorward of $15 \mathrm{~N} / \mathrm{S}$, as thermal wind balance is not a good approximation in the tropics. For Fig. 3b, Arctic amplification and lower tropospheric wind anomalies are removed by setting the near-surface zonal mean wind anomalies to zero and zonal mean $T$ anomalies to $4 \mathrm{~K}$ everywhere below 0.5 . Polar lower stratospheric cooling is removed by setting zonal mean $T$ anomalies poleward of $42^{\circ} \mathrm{N}$ and between $\sigma=0.07$ and $\sigma=0.3$ to zero.

Stationary wave theory. Results are interpreted using linear barotropic Rossby wave theory. The assumption of linearity is reasonable as we obtain similar conclusions with linear stationary wave model simulations. The relevant waves are deep barotropic structures, and therefore will be influenced by the winds throughout their depth (which extends above $100 \mathrm{hPa}$ ). Throughout this discussion we assume that the larger zonal wind changes at $100 \mathrm{hPa}$ are, therefore, having an influence on the wave structures throughout the depth of the troposphere, and we make use of the wind anomalies at this level for the regression in Fig. 5, as it is where the anomalies are largest.

\section{References}

28. Ting, M. \& Yu, L. Steady response to tropical heating in wavy linear and nonlinear baroclinic models. J. Atmos. Sci. 55, 3565-3582 (1998).

29. Nigam, S., Held, I. M. \& Lyons, S. W. Linear simulation of the stationary eddies in a general circulation model. Part 1: The no-mountain model. J. Atmos. Sci. 43, 2944-2961 (1986). 